\title{
LIČNOST ŽENA OBOLJELIH OD KARCINOMA DOJKE
}

\author{
Andrea Vlašić \\ Asocijacija psiholoških i poligrafskih ispitivanja, Livno, Bosna i Hercegovina \\ Rad je primljen 20.4.2017. Rad je recenziran 25.4.2017. Rad je prihvaćen 3.5.2017.
}

\section{SAŽETAK}

UVOD: Karcinom dojke je veliki zdravstveni problem suvremenog doba, posebno jer sve češće obolijevaju i vrlo mlade žene. Iako je otkriveno nekoliko rizičnih faktora prvog reda, oni objašnjavaju tek $25 \%$ svih vrsta karcinoma. Rizične faktore tražimo i među psihološkim faktorima. Dosadašnja istraživanja o povezanosti faktora ličnosti i karcinoma dojke dala su nekonzistentne rezultate. Cilj istraživanja je ispitati potencijalne razlike u crtama ličnosti između ispitanica s karcinomom dojke, te ispitanica koje nisu imale nikakav oblik karcinoma u povijesti bolesti.

ISPITANICI I METODE: U istraživanju je sudjelovalo 40 žena koje su članice udruga oboljelih od raka dojke iz Mostara, Zagreba i Livna, te 39 žena bez karcinoma koje po dobi odgovaraju ispitivanoj skupini. Upotrijebljen je sociodemografski upitnik i upitnik ličnosti NEO PI-R.

REZULTATI: Ispitane su razlike na pet glavnih faktora ličnosti (Neuroticizam, Ekstraverzija, Savjesnost, Ugodnost, Otvorenost ka iskustvima) i 30 faceta ličnosti. Rezultati su pokazali da se ispitivana i kontrolna skupina statistički značajno ne razlikuju na pet glavnih faktora ličnosti, ali je uočena značajna veza karcinoma dojke s do sad neistraženom facetom ličnosti „Vrijednosti“.

ZAKLJUČAK: Istraživanje ukazuje da nema razlike između ispitivanih skupina na pet glavnih crta ličnosti s karcinomom dojke, ali da postoji razlika između ispitanica s karcinomom dojke i zdravih ispitanica kada su u pitanju nadlične vrijednosti.

Ključne riječi: crte ličnosti, karcinom dojke, psihoonkologija.

Osoba za razmjenu informacija:

Vlašić Andrea, doktorand psihologije

e-mail: andrea2304@gmail.com

\section{UVOD}

Uloga ličnosti kao predispozicijskog faktora za karcinom tema je kontroverze koja traje desetljećima. Sve ono što povećava vjerojatnost oboljenja od određenog poremećaja kod pojedinca naziva se rizičnim faktorom za tu bolest. Neki rizični faktori proizlaze iz bioloških i okolinskih uvjeta, poput genetskih defekata ili izloženosti otrovnim kemikalijama, dok se drugi javljaju u obliku obrazaca ponašanja koji su zdravstveno rizični (1).

Domena prilagodbe se odnosi na činjenicu o ključnoj ulozi ličnosti u načinu suočavanja s događajima u našem svakodnevnom životu, ali i prilagodbi (2). Personalna postavka upućuje na mogućnost povezanosti crta ličnosti i zloćudnih tumora i usko je povezana s genetskom postavkom, jer su mnoge crte ličnosti oblikovane pod genetskim utjecajem (3).

Osobine ličnosti na tri načina povećavaju vjerojatnost pojave bolesti, posebno kod ljudi koji imaju i genetsku predispoziciju za neku bolest, i to povećanjem fiziološke aktivacije, smanjivanjem socijalne potpore, te interferiranjem sa zdravim ponašanjem (4).

Istraživanja provedena radi utvrđivanja povezanosti zloćudnih tumora s pojedinim crtama ličnosti upućuju na postojanje pozitivne korelacije između pojavnosti raka, niskih rezultata na skalama Neuroticizma i visokih na skali Ekstraverzije $(5,6,7)$. Razrađena je postavka o tome kako niski Neuroticizam 
može u stvari značiti izostanak emocionalnog doživljavanja, pa možda i potiskivanje emocija. Bilo bi onda za očekivati da osobe s visokim stupnjem emocionalnosti (koji je npr. prisutan kod nekih psihoza), nisu toliko izložene karcinomu (5). Drugi autori su sukladno tomu ustanovili da među duševnim bolesnicima i osobito oboljelima od shizofrenije postoji manji broj oboljelih od karcinoma nego u općoj populaciji, pa je broj duševnih bolesnika s karcinomom manji za trećinu, nego što je to slučaj kod ostalog stanovništva (8). Prema epidemiološkim podacima iz Engleske i Walesa, prema kojima je $20 \%$ ukupne smrtnosti stanovništva prouzročeno zloćudnim novotvorinama, u usporedbi sa svega $7 \%$ u skupini duševnih bolesnika (9).

Već početkom 60 -ih godina 20. stoljeća nekoliko istraživača uočilo je i potvrdilo vezu karcinoma $s$ takozvanim ponašanjem Tipa $C$ ili tzv. ličnošću sklonom razvoju karcinoma (5). Ljude s takvom ličnošću opisujemo kao pretjerano sklone konformiranju i emocionalno otupjelima. To su ljudi koji djeluju mirno i sabrano, pri čemu ulažu velike napore u nijekanje i potiskivanje svoje uznemirenosti (4). Osobe Tipa $\mathrm{C}$ u susretu sa životnim stresorima osjećaju nemoć, te beznadnost situacije. S druge strane, empirijski podaci o postojanju veze između ličnosti Tipa C i karcinoma su slabi, a rezultati dobiveni u longitudinalnim istraživanjima koja su pokušavala predvidjeti pojavu karcinoma na temelju procjene ličnosti - proturječni (4).

Istraživanja provedena u posljednjih 15 godina ne pokazuju povezanost crta ličnosti kao što su Neuroticizam i Ekstraverzija s pojavnošću karcinoma ili smrtnosti od karcinoma $(10,11)$. Ova istraživanja pretpostavljaju da se pozitivna korelacija crta ličnosti i pojavnosti karcinoma u ranijim istraživanjima javljala zbog metodoloških problema, no metodološke kritike možemo uputiti i onim istraživanjima koja nisu dokazala tu vezu. Neke od kritika su mali uzorci, izuzetno kratki upitnici kojima se ispitivala ličnost (samo 18 čestica), te ispitivanje samo Ekstraverzije i Neuroticizma.

Statistički značajna veza nađena je između niskih rezultata na skali Neuroticizma i rizika od karcinoma dojke na uzorku od 75 žena, ali nije pronađena veza između povećanog rizika od karcinoma s rezultatima na skali Ekstraverzije (12). Usporedbom 75 žena sa i 17 bez karcinoma dojke pokazalo se da su žene s karcinomom dojke, između ostalog, bile manje anksiozne, rjeđe su iskazivale ponašanje Tipa A, a više socijalne poželjnosti. No, autor spomenute studije nije uspio replicirati rezultate u novoj studiji 6 godina kasnije (13).

U velikoj prospektivnoj longitudinalnoj studiji ispitivan je odnos faktora ličnosti i razvoja karcinoma (14). Upotrijebljen je upitnik ličnosti posebno pripremljen za ovu priliku, a kojim se mjerilo 11 crta ličnosti. Rezultati su pokazali da od ispitivanih psiholoških varijabli tek slabu povezanost s rakom dojke ima jedino anti-emocionalnost. To vodi do zaključka da žene koje su manje sklone vjerovati vlastitim osjećajima i nerado dozvoljavaju emocijama da utječu na njihovo ponašanje imaju u prosjeku veći rizik obolijevanja od karcinoma dojke (14). Istraživanja su pokazala veću sklonost depresivnih žena razvoju karcinoma dojke, dok su druga istraživanja pokazala upravo suprotno $(15,16)$.

Kontradiktorni rezultati djelomično se mogu objasniti različitim nacrtima istraživanja. Rezultati su očigledno nekonzistentni i do sada se nisu mogli donijeti konačni zaključci o vezi crta ličnosti i karcinoma dojke, te je potrebno nastaviti s istraživanjima u ovom području.

Cilj ovog istraživanje je ispitati da li su kod ispitivane skupine u odnosu na kontrolnu izraženije crte ličnosti Neuroticizam, Savjesnost i Ugodnost, te provjeriti razlikuju li se međusobno ispitivana $\mathrm{i}$ kontrolna skupina na crtama ličnosti Otvorenost ka iskustvima i Ekstraverzija, te opisati značajne razlike u facetama ličnosti.

\section{ISPITANICI I METODE}

$\mathrm{U}$ istraživanju je sudjelovalo 79 ispitanica od 31 do 64 godine, prosječne dobi 46,6 godina ( $\sigma=10,3$; $\mathrm{N}=79)$. Ispitivanu skupinu $(\mathrm{n}=40)$ čine članice nevladinih udruga žena oboljelih od karcinoma dojke iz Mostara, Livna i Zagreba, a kontrolnu $(n=39)$ ispitanice koje su po dobi izjednačene ispitanicama ispitivane skupine, ali u svojoj povijesti bolesti nemaju dijagnozu karcinoma bilo kojeg 
oblika. Prosječna dob ispitanica ispitivane skupine je 47,3 ( $\boldsymbol{\sigma}=9,9 ; n=40)$, a kontrolne 45,9 $(\boldsymbol{\sigma}=10,8$; $\mathrm{n}=39)$. Da bismo provjerili razlikuju li se statistički značajno ove dvije skupine prema dobi, proveli smo t-test za velike nezavisne uzorke, te dobili da između ispitivane i kontrolne skupine ne postoji statistički značajna dobna razlika $(\mathrm{t}=0,58 ; \mathrm{df}=77 ; \mathrm{p}>0,05)$.

Podaci su se prikupljali tijekom ožujka 2017. godine dobrovoljnim, anonimnim ispunjavanjem online upitnika. Ispitanice su u uvodu ukratko upoznate s temom i svrhom istraživanja i načinom popunjavanja instrumenta, te su nakon informiranog pristanka pristupile samostalnom online popunjavanju materijala. Ispitanicama se zajamčila anonimnost time što su sudjelovale $u$ online istraživanju, bez potrebe upisivanja ikakvih osobnih podataka kojima bi se mogao razotkriti identitet. Ponuđena je i alternativna mogućnost sudjelovanja u istraživanju putem papir-olovka anketiranja, u slučaju da nisu vješte u uporabi računala $\mathrm{i} / \mathrm{ili}$ interneta.

U ukupnom uzorku ( $\mathrm{N}=79)$, njih $40,5 \%$ je zaposleno, 30,4 \% nezaposleno, a 29,1\% umirovljeno. Više od polovine ispitanica (51,9 \%) je najveći dio života provelo na selu, a preostalih $48,1 \%$ u gradu. Najviše ispitanica je u bračnoj zajednici (59,5 \%), potom udovica $(26,6 \%)$, samica $(12,6 \%)$, a najmanje je razvedenih (1,3\%).

Za ovo istraživanje sastavljen je kratki upitnik koji je uključivao socio-demografska pitanja (spol, dob, radni i bračni status, sredinu gdje je ispitanica provela najveći dio života) i pitanja o bolesti (fazi karcinoma (u ispitivanoj skupini), bolovanje od drugih bolesti osim karcinoma). Za ispitivanje crta ličnosti upotrijebljen je NEO PI-R upitnik (17). Ovaj upitnik se sastoji od 240 tvrdnji i standardizirana je mjera petofaktorskog modela ličnosti. Rezultati na NEO PI-R upitniku daju nam temeljitu procjenu normalne ličnosti opisujući 5 glavnih crta ličnosti uključujući po 6 faceta koje definiraju svaku od crta ličnosti. Crte ličnosti koje se procjenjuju su: Neuroticizam, Ekstraverzija, Savjesnost, Otvorenost ka iskustvima i Ugodnost. Pouzdanost NEO PI-R upitnika određena Cronbachovim alfa koeficijentom na podacima dobivenim u ovom istraživanju je visoka $i$ iznosi 0,896 (pouzdanost 5 skala koje mjere faktore ličnosti su također visoki i kreću se od 0,88 do 0,95 ).

$\mathrm{Za}$ obradu i analizu podataka upotrijebljen je programski sustav SPSS for Windows (inačica 20.0, SPSS Inc, Chicago, Illinois, SAD). Kategoričke varijable su prikazane kao frekvencije ili postotci. Rezultati dobiveni primjenom NEO PI-R upitnika prikazani su deskriptivnim parametrima za svaki od pet faktora ličnosti za ispitivanu i kontrolnu skupinu: prosječna vrijednost (medijan), raspršenje rezultata oko prosjeka (interkvartilni raspon). Procjenu normalnosti distribucije rezultata na pet faktora ličnosti i 30 faceta kod ispitivane i kontrolne skupine vršili smo Shapiro-Wilkovim testom, te sukladno rezultatima upotrijebili odgovarajuće parametrijske (t-test) ili neparametrijske (Mann-Whitney) statističke postupke. Statistička značajnost određena je uz rizik od pogreške 5 \% i $1 \%$.

\section{REZULTATI}

Tablica 1. Deskriptivni parametri 5 faktora ličnosti zasebno za ispitivanu $(n=40)$ i kontrolnu $(n=39)$ skupinu

\begin{tabular}{|c|c|c|c|c|c|c|}
\hline \multirow{3}{*}{ NEO PI-R } & \multicolumn{4}{|c|}{ Skupina } & \multirow{3}{*}{ U } & \multirow{3}{*}{ p } \\
\hline & \multicolumn{2}{|c|}{ Kontrolna (N=39) } & \multicolumn{2}{|c|}{ Ispitivana (N=40) } & & \\
\hline & M & IR & M & $\mathbb{I R}$ & & \\
\hline Neuroticizam & 112,00 & 30,00 & 106,00 & 42,50 & 699,0 & 0,427 \\
\hline Ekstraverzija & 154,00 & 33,00 & 159,50 & 32,25 & 726,5 & 0,600 \\
\hline Otvorenost & 159,00 & 28,00 & 171,00 & 26,00 & 602,0 & 0,081 \\
\hline Ugodnost & 175,00 & 34,00 & 170,50 & 28,25 & 701,5 & 0,441 \\
\hline Savjesnost & 177 & 30,00 & 174,00 & 37,25 & 754,5 & 0,802 \\
\hline Vrijednosti & 29,00 & 7,00 & 32,00 & 8,00 & 514 & $<0,001$ \\
\hline
\end{tabular}

Statističkom analizom pokazalo se da rezultati ispitivane skupine na svih 5 faktora ličnosti značajno odstupaju od normalne raspodjele kao i rezultati kontrolne skupine na faktorima Otvorenost i Ugodnost. Rezultati dobiveni provedbom neparametrijskog testa za velike nezavisne uzorke upućuju na zaključak da dobivene razlike na svih pet faktora ličnosti 
u našem istraživanju nisu statistički značajne (tablica 1). Ispitanice koje su bolovale od karcinoma dojke su podjednako emocionalno stabilne, ekstravertirane, otvorene, ugodne i savjesne kao i ispitanice koje nisu bolovale niti od jedne vrste karcinoma.

Daljnjom analizom potencijalnih razlika koje bi mogle diferencirati ispitanice ispitivane $i$ kontrolne skupine, provjeravali smo rezultate koje su postizale na facetama ličnosti. Kako distribucije rezultata na facetama značajno odstupaju od normalnih, razlike su testirane neparametrijskim postupcima. Značajno je za spomenuti da smo uočili samo jednu statistički značajnu razliku, koja do sad nije spominjana $u$ ranijim istraživanjima. Radi se o razlici na faceti „Vrijednosti“. Ispitanice ispitivane skupine su postizale statistički značajno više prosječne rezultate na ovoj faceti od ispitanica kontrolne skupine (tablica 1).

Konkretno, ispitanice kontrolne skupine su se češće od ispitanica ispitivane skupine slagale s tvrdnjama prikazanim u tablici 2 , dok su se ispitanice ispitivane skupine češće slagale od ispitanica kontrolne skupine s tvrdnjama prikazanim u tablici 3.

Tablica 2. Tvrdnje koje čine skalu „Vrijednosti“, a s kojima su se ispitanice kontrolne skupine češće pokazivale viši stupanj slaganja $u$ odnosu na ispitanice ispitivane skupine.

- Mislim da zakone i socijalnu politiku treba mijenjati u skladu s potrebama svijeta koji se mijenja.

- Vjerujem da je normalno da ljudi u različitim društvima imaju različita mišljenja o ispravnom i pogrešnom.

- Mislim da sam osoba otvorenog duha i tolerantna prema načinu života drugih ljudi.

Tablica 3. Tvrdnje koje čine skalu „Vrijednosti“, a s kojima su se ispitanice kontrolne skupine češće pokazivale niži stupanj slaganja u odnosu na ispitanice ispitivane skupine.

- Vjerujem da studente može samo zbuniti i zavesti ako čuju proturiječne govornike.

- Vjerujem da bismo se trebali obraćati našim crkvenim poglavarima radi donošenja odluka o moralnim problemima.
- Mislim da je vjernost vlastitim principima i idealima važnija nego otvorenost prema novim idejama.

- Ako ljudi do svoje dvadeset i pete godine života ne znaju u šta vjerovati, mislim da nešto nije u redu s njima.

- Vjerujem da popustljivost u pitanjima morala znači zapravo nemoral.

\section{RASPRAVA}

Rezultati našeg istraživanju su pokazali da se ispitivana i kontrolna skupina statistički značajno ne razlikuju na pet glavnih faktora ličnosti, ali je uočena značajna veza karcinoma dojke s do sad neistraženom facetom ličnosti „Vrijednosti“.

Kako smo već rekli, istraživanja provedena radi utvrđivanja povezanosti zloćudnih tumora s pojedinim crtama ličnosti upućuju na postojanje pozitivne korelacije između pojavnosti raka, niskog Neuroticizma i visoke Ekstraverzije $(5,6,7)$. Konkretno, razrađena je pretpostavka da niski Neuroticizam može u stvari značiti izostanak emocionalnog doživljavanja, pa možda i potiskivanje emocija (5). Bilo bi stoga za očekivati da osobe s visokim stupnjem emocionalnosti nisu toliko izložene karcinomu. Rezultati našeg istraživanja pokazuju da rezultati idu upravo u tom smjeru - ispitanice s karcinomom dojke imale su nešto niže rezultate na skali Neuroticizma od ispitanica kontrolne skupine, ali i nešto više na skali Ekstraverzije, no te razlike se nisu pokazale statistički značajne. Statistički značajna veza nađena je između niskih rezultata na skali Neuroticizma i rizika od karcinoma dojke, ali veza između povećanog rizika i rezultata na skali Ekstraverzije nije potvrđena (12). Jedna od najnovijih meta-analiza povezanosti crta ličnosti i različitih oblika karcinoma, među kojima je i karcinom dojke kod žena, također potvrđuje da u dosadašnjim istraživanjima nije potvrđena veza između pet glavnih faktora ličnosti i rizika od karcinoma odnosno stope smrtnosti od karcinoma (18).

Najzanimljiviji dio našeg istraživanja je neočekivana faceta ličnosti koja se pokazala kao crta koja čini razliku između ispitivane i kontrolne skupine. Radi se o faceti „Vrijednosti“, koja čini jednu od 6 
specifičnih crta koje skupa čine faktor Otvorenost ka iskustvima. Zanimljivo je to što „Vrijednosti“ još nisu spominjane u ranijim istraživanjima kao mogući faktor koji diferencira ispitanike $s$ karcinomom od kontrolne skupine odnosno kao faktor koji predviđa povećani rizik od obolijevanja od karcinoma. Kao što smo vidjeli u prikazu rezultata, ispitanice s karcinomom dojke postigle su statistički značajno više rezultate na skali „Vrijednosti“ od ispitanica kontrolne skupine uz stupanj sigurnosti $99 \%$. Ovakav rezultat govori da su ispitanice bez karcinoma dojke u svojoj povijesti bolesti sklonije liberalizmu, tolerantnom i otvorenom društvu, otvorenije su novim $\mathrm{i}$ alternativnim idejama $\mathrm{u}$ odnosu na ispitanice kontrolne skupine koje su manje liberalnog razmišljanja, strožih moralnih kriterija i podložnije vanjskim moralnim autoritetima. Viši rezultat na ovoj skali govori o sklonosti ka nadličnim vrijednostima - otvorenost u odnosu na vrijednosti, spremnost za preispitivanje socijalnih, političkih i religioznih vrijednosti. Otvorenost vrijednostima znači spremnost za propitivanje vrijednosti (socijalnih, političkih i religioznih). Pojedinci nisko na ovoj faceti skloni su prihvatiti autoritete i držati do tradicije, te su općenito konzervativni bez obzira kojoj političkoj opciji su skloni. Otvorenost vrijednostima može se smatrati suprotnošću dogmatizmu.

Iako je u ovom istraživanju pronađena statistički značajna razlika na skali „Vrijednosti“, potrebno je nastaviti istraživanja u ovom smjeru, ispitujući temeljitije ovu facetu ličnosti i njenu povezanost s pojavnošću karcinoma dojke.

Među glavnim nedostacima ovog istraživanja je mali broj ispitanika. Iako je za ispitivanu studiju ovo dovoljno velik uzorak, s većim i bolje selekcioniranim uzorkom dobili bismo podatke na kojima bismo mogli provesti robustnije statističke testove. Nadalje, ispitivanje ličnosti bi trebalo obaviti prije dijagnoze karcinoma, te potom usporediti žene kojima je dijagnosticiran karcinom dojke sa ženama iste dobi kojima do tog trenutka karcinom nije dijagnosticiran. Druga mogućnost je ispitati ličnost na dovoljno velikom broju ispitanica kojima je tek dijagnosticiran karcinom, onima koje se već liječe od karcinoma, ispitanicama koje su već prošle liječenje i smatraju se izliječenima, te ispitanicama koje su i nakon liječenja imale recidiv ili metastaze.

Za buduća ispitivanja predlažemo provođenje prospektivnih, longitudinalnih studija, ispitivanje ličnosti u širem kontekstu, ali ne samo kao uzroka karcinoma, nego i kao zaštitnog faktora (npr. stres kao uzrok, a ličnost kao prva crta obrane od stresa). Također predlažemo proučavanje potencijalnih promjena u ličnosti prije dijagnosticiranja karcinoma i nakon liječenja, ali i ispitivanje ličnosti kod drugih vrsta karcinoma, a ne samo karcinoma dojke. Poželjno bi bilo imati dovoljno dobar ispitivani, ali i kontrolni uzorak $\mathrm{u}$ istraživanju radi ispunjavanja preduvjeta za logističku regresiju, kojom bismo mogli provjeriti koliko se mogu predvidjeti zdravstveni ishodi na temelju ispitivanih crta ličnosti.

\section{ZAKLJUČAK}

Ispitanice s karcinomom dojke ne razlikuju se statistički značajno od ispitanica kontrolne skupine na crtama ličnosti Neuroticizam, Ekstraverzija, Savjesnost, Ugodnost i Otvorenost ka iskustvima u ovom istraživanju, ali postižu značajno više rezultate na faceti ličnosti „Vrijednosti“ što govori o većoj sklonosti prihvaćanju autoriteta kod ispitanica s karcinomom dojke.

\section{LITERATURA}

1. Stokols D. Establishing and maintaining healthy environments: Toward a social ecology of health promotion. Am Psychol 1992; 47:6-22.

2. Larsen RJ, Buss DM. Psihologija ličnosti: Područja znanja o ljudskoj prirodi. Jastrebarsko: Naklada Slap, 2008.

3. Havelka M. Zdravstvena psihologija. Zagreb: Medicinski fakultet Sveučilišta u Zagrebu, 1995.

4. Nietzel MT, Bernstein DA, Milich R. Uvod u kliničku psihologiju. Jastrebarsko: Naklada Slap, 2002.

5. Kissen DM, Eysenck HJ. Personality in male lung cancer patients. J Psychosom Res 1962; 6:123127.

6. Greer S, Morris T. Psychological attributes of women who develop breast cancer: a controlled study. J Psychosom Res 1975; 19:147-153. 
7. Berndt H, Gunther H, Rothe G. Stress and Cancer. Toronto, C.J. Hogrefe, 1980.

8. Rassidakis NC, KeJepouris M, Fox S. Malignant neoplasm as a cause of deaths among psychiatric patients. Int Ment Health Res Newsletter 1971; 13:3-6.

9. Eysenck HJ. The Causes and Effects of Smoking. London: Maurice Temple Smith, 1980.

10. Schapiro IR, Ross-Petersen L, Saelan H, Garde K, Olsen JH, Johansen C.Extroversion and Neuroticism and the Associated Risk of Cancer: A Danish Cohort Study. Am J Epidemiol 2001; 153:75763.

11. Nakaya N, Bidstrup PR, Saito-Nakaya K i sur. Personality Traits and Cancer Risk and Survival Based on Finnish and Swedish Registry Data. Am J Epidemiol 2010; 172:377-85.

12. Morris T, Greer S, Pettingale KW i sur. Patterns of expression of anger and their psychological correlates in women with breast cancer. J Psychosom Res 1981; 25:111-17.

13. Scherg H. Psychosocial factors and disease bias in breast cancer patients. Psychosom Med 1987; 49:302-312.
14. Bleiker EMA, Ploeg HM, Hendriks JHCL i Ader HJ. Personality Factors and Breast Cancer Development: a Prospective Longitudinal Study. J Natl Cancer Inst 1996; 88:1478-82.

15. Persky VW, Kempthorne-Rawson J, Shekelle, R.B. Personality and risk of cancer: 20-year follow-up of the Western Electric Study. Psychosom Med 1987; 49:435-49.

16. Dattore PJ., Shontz FV, Coyne L. Premorbid personality differentiation of cancer and noncancer groups: a test of the hypothesis of cancer proneness. J Consult Clin Psychol 1980; 48:388-94.

17. Marušić I, Bratko D. Prijevod, adaptacija i validacija NEO PI-R upitnika ličnosti. U: NEO PI-R Revidirani NEO inventar ličnosti, priručnik, Naklada Slap, 2004.

18. Jokela M, Batty GD, Hintsa T, Elovainio M, Hakulinen, C., Kivimaki, M. Is personality associated with cancer incidence and mortality? An individual participant meta-analysis of 2156 incident cancer cases among 42843 men and women. BrJ Cancer 2014; 110:1820-4. 


\title{
PERSONALITY TRAITS OF WOMEN WITH BREAST CANCER
}

\author{
Andrea Vlašić
}

Association of Psychological and Polygraph Examinations, Livno, Bosnia and Herzegovina

\begin{abstract}
INTRODUCTION: Breast cancer is a major health problem of the modern age, especially because it affects young women. Although several first-rate risk factors have been discovered, they explain only $25 \%$ of all types of cancer. We also look for risk factors among psychological factors. Previous studies on the relationship between personality factors and breast cancer have produced inconsistent results. The objective of the study was to examine potential differences in personality traits among breast cancer patients and subjects without any form of cancer in their medical history.

SUBJECTS AND METHODS: The study included 40 women who are members of breast cancer associations from Mostar, Zagreb and Livno, and 39 women without cancer who are the same age as women from the study group. We used the socio-demographic questionnaire and NEO Personality Inventory.

RESULTS: Five major domains of personality (Neuroticism, Extraversion, Openness to Experience, Agreeableness and Conscientiousness) and 30 facet scales were examined. The results showed that the study and control group did not differ significantly in the five major domains of personality, but there was a significant link between breast cancer and the unexamined facet of "Values".

CONCLUSION: The study suggests that there is no difference between the examined groups on the five major domains of personality and breast cancer, but there is a difference between breast cancer patients and healthy subjects when it comes to super personal values.
\end{abstract}

Key words: personality traits, breast cancer, psychooncology

Correspondence:

Vlašić Andrea, doctoral student of psychology

e-mail: andrea2304@gmail.com 